\title{
Efecto del uso de quitosano en el mejoramiento del cultivo del arroz (Oryza sativa L. variedad sd20a)
}

\section{Effect of the use of chitosan in the improvement of rice cultivation (Oryza sativa L. variety sd20a)}

\author{
Efeito do uso de quitosano na melhoria da cultura \\ do arroz (Oryza sativa L. variedade sd20a)
}

\section{José Alejandro Molina Zerpa', Marinela Colina Rincón², Dianela Rincón ${ }^{3}$ \& José Alejandro Vargas Colina ${ }^{4}$}

\begin{abstract}
'Licenciado en Química, Magister en Ciencias Ambientales. ${ }^{2}$ Ingeniero Químico, Magister en Ingeniería Ambiental, Doctor en Química Analítica Ambiental. ${ }^{3}$ Licenciada en Química, Magister en Ingeniería Ambiental. 4Ingeniero Electrónico

1,2,3Innovación Ambiental Quitosano. Zulia, Venezuela. 2,4Universidad del Zulia. Zulia,Venezuela.

1josealejandro.molina@gmail.com; ${ }^{2}$ colinamarinela@gmail.com; 3rincondianela@gmail.com; ‘josealejandro.vargas@gmail.com
\end{abstract}

\section{Resumen}

En la actualidad existen alternativas tecnológicas para el aprovechamiento de los desechos de crustáceos y su conversión en productos de utilidad como lo son la quitina y su derivado el quitosano. En esta investigación, se utilizó gel de quitosano para aplicarlo a la variedad de arroz SD20 para mejorar su cultivo. El análisis mediante IR del quitosano utilizado mostró similitud con los espectros para cada una de las muestras, confirmando con estos resultados que la utilización de diferentes quitinas obtenidas por la desmineralización con $\mathrm{HCl}$ y $\mathrm{H}_{3} \mathrm{PO}_{4}$ no afectó la identidad del producto, pues se mantienen las bandas de los grupos funcionales más importantes, demostrándose así que las quitinas se transformaron en una nueva materia prima como el quitosano. Las plantas tratadas con quitosano presentaron alturas mayores, con incrementos de altura hasta de 16,57\% en comparación al testigo. Además, produjo un incremento de la raíz de 52\% para los 12 días de siembra en comparación con el testigo. Se observó en las plantas de arroz un color verde más intenso que en lote testigo, estos resultados se deben a la capacidad estimulante del quitosano, ya que actúa mejorando el enraizamiento y la producción de área foliar de la planta. Se encontró una diferencia de $1025 \mathrm{~kg} / \mathrm{ha}$, y un incremento en la cosecha de $16,21 \%$ con respecto al tratamiento sin quitosano. Se concluye que el cultivo de arroz, variedad SD20A, tuvo un desarrollo vegetativo mejor con el tratamiento con quitosano.

Palabras clave: desecho de crustáceo, quitina, rendimiento

\section{Abstract \\ Currently there are technological alternatives for the use of shellfish waste and its conversion into useful products such as chitin and its derivative chitosan.}


In this research, we used chitosan gel to apply it to the variety of rice SD20 to improve its cultivation. The analysis by IR of the chitosan used showed similarity with the spectra for each of the samples, confirming with these results that the use of different chitins obtained by demineralization with $\mathrm{HCl}$ and $\mathrm{H}_{3} \mathrm{PO}_{4}$ did not affect the identity of the Product, as the bands of the most important functional groups are kept, demonstrating so that the chitins transformed into a new raw material like the chitosan. The plants treated with chitosan showed higher heights, with height increase of up to $16.57 \%$ compared to the control. In addition, it produced an increase of the root of $52 \%$ for the 12 days of sowing compared with the control. It was observed in the rice plants a green color more intense than in witness lot, these results are due to the stimulating capacity of the chitosan, as it acts improving the rooting and the production of foliar area of the plant. We found a difference of $1025 \mathrm{~kg} / \mathrm{ha}$, and an increase in the harvest of $16.21 \%$ with respect to treatment without chitosan. It is concluded that the cultivation of rice, SD20A variety, had a better vegetative development with the treatment with chitosan.

Key-words: shellfish disposal, chitin, yield

\section{Resumo}

Atualmente, existem alternativas tecnológicas para o uso de resíduos de crustáceos e sua conversão em produtos úteis, como a quitina e sua derivada de quitosana. Nesta pesquisa, o gel de quitosana foi utilizado para aplicá-lo à variedade de arroz SD20 para melhorar sua cultura. A análise de IR da quitosana utilizada mostrou similaridade com os espectros para cada uma das amostras, confirmando com estes resultados que o uso de diferentes quitinas obtidas pela desmineralização com $\mathrm{HCl}$ e $\mathrm{H}_{3} \mathrm{PO}_{4}$ não afetou a identidade do produto, pois as bandas de os grupos funcionais mais importantes, provando que as quitinas foram transformadas em uma nova matéria-prima, como a quitosana. As plantas tratadas com quitosana apresentaram alturas mais altas, com aumentos de até $16,57 \%$ em relação ao controle. Além disso, produziu um aumento de raiz de $52 \%$ nos 12 dias de semeadura em relação ao controle. Uma cor verde mais intensa foi observada nas plantas de arroz do que no lote de controle, esses resultados são devidos à capacidade de estimulação do quitosano, pois atua para melhorar o enraizamento e a produção da área foliar da planta. Foi encontrada uma diferença de $1025 \mathrm{~kg} /$ ha e um aumento na colheita de $16,21 \%$ em relação ao tratamento sem quitosana. Conclui-se que o cultivo de arroz, variedade SD20A, teve um melhor desenvolvimento vegetativo com tratamento com quitosana.

Palavras chave: desperdício de crustáceos, quitina, rendimento

\section{Introducción}

La extracción de quitina en el proceso para la obtención de su derivado el quitosano, juega un papel muy importante porque de ella se derivan muchas variables en el resultado del producto final, desde la masa molar del polímero, hasta la cantidad de material insoluble que pueda presentar el quitosano, así como también la disminución o aumento del efecto bactericida, fungicida, grado de pureza, formación de películas entre otras (Colina et al., 2014). Además como regulador del crecimiento el quitosano acelera la germinación de las semillas, el vigor de las plantas y el rendimiento agrícola. El arroz, Oryza sativa L., después del trigo, es el cereal más cultivado en el mundo, siendo base de la alimentación de más de la mitad de los habitantes del planeta. En Venezuela el arroz, junto con el maíz, Zea mays L., corresponden a los principales cereales cultivados, por esto en la presente investigación se evaluó el quitosano a nivel industrial para aplicarlo en el mejoramiento del cultivo de arroz.

El Quitosano es un derivado de la quitina, siendo un continuo de diferentes copolímeros de unidades de glucosamina $\mathrm{N}$-acetil-D-glucosamina y se diferencia de la quitina por grupos amina- $\mathrm{NH}_{2}$, como se observa en la Figura 1. 


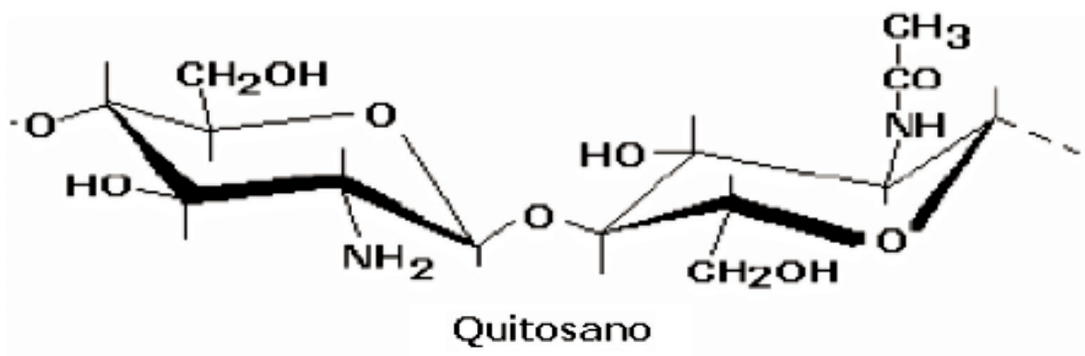

Figura 1. Estructura del Quitosano.

En medio ácido, el quitosano tiene más de un centro reactivo, a través de sus funciones y el alcohol amino. Debido a su biodegradabilidad y no toxicidad residual, su naturaleza polielectrolítico y su tendencia a la floculación, el polímero de quitosano posee un sin fin de aplicaciones, seguramente muchas aún por descubrir. (Aranaz et al., 2009; Costa et al., 2015; Zemmouri et al., 2012).

El quitosano se caracteriza fundamentalmente por su masa molecular (MM) y el grado de desacetilación (GDA). Esta comercialmente disponible normalmente de (GDA: Grado de desacetilación) GDA $>85 \%$ de unidades desacetilado (GD $<15 \%$ ), y masa molecular (MM) entre 100 y 1000 kDa (Kasaai, 2008; Costa et al., 2015). El quitosano es una base débil y es insoluble en agua, pero soluble en una disolución acida con un pKa $(\sim 6,3)$, en la que puede convertir las unidades de glucosamina $\left(-\mathrm{NH}_{2}\right)$ en la forma soluble protonada $\left(-\mathrm{NH}_{3}{ }^{+}\right)$. La solubilidad del quitosano depende de su origen biológico, el peso molecular y grado de acetilación (Nieto et al., 1991).

La Figura 2, muestra algunas generalidades en las aplicaciones del quitosano, las cuales son cada vez más extensas por el uso progresivo de este polímero y las numerosas investigaciones que se están llevando a cabo (Kurita, 2006; Valenzuela et al., 2012).

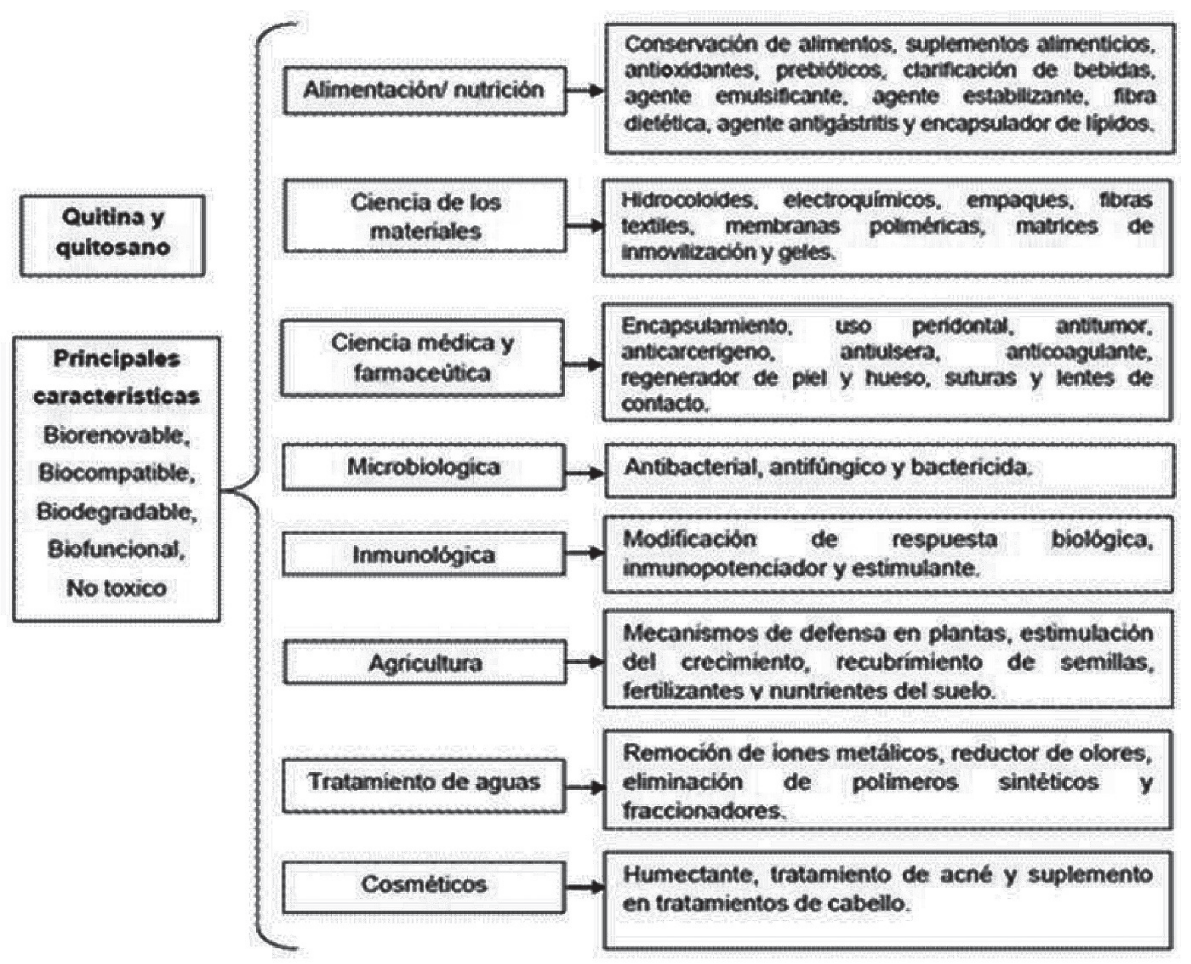

Figura 2. Aplicaciones generales del polímero quitosano 
El quitosano tiene acción antimicrobiana en alimentos, se ha descrito su acción in vitro sobre patógenos contaminantes de productos cárnicos y cecinas mencionando entre los principales, Escherichia coli, causante de graves complicaciones como la colitis hemorrágica y el síndrome urémico hemorrágico, y que su mayor fuente de infección son los alimentos de origen animal, principalmente carne de vacuno molida y leche cruda, Escherichia coli (Li et al.,
2006; Xing et al., 2009); Staphylococcus aureus (Li et al., 2006); Listeria monocito genes (Li et al., 2006, Valbuena et al., 2012).

La carga positiva que se desarrolla en el quitosano en medio acido ( $\mathrm{pH}<5,5)$ (Figura 3), debido a la protonación del grupo amino presente en cada una de las unidades glucosamina, lo hace soluble en medio acuoso, confiriéndole mayor actividad biocida.

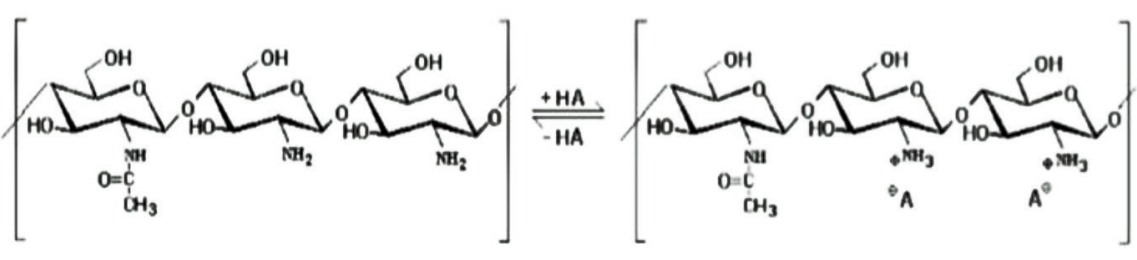

Figura 3. Estructura química del quitosano en función del pH del medio.

Los mecanismos de acción por los cuales el quitosano y sus derivados ejercen dicha actividad no han sido dilucidados completamente; sin embargo, hay algunos mecanismos propuestos para explicar acciones específicas como por ejemplo: La interacción electrostática entre el quitosano cargado positivamente (polielectrolito catiónico) y algunas bacterias con membranas celulares cargadas negativamente (Gram negativas como la Echerichia coli, Pseudomonas aeruginosa, Staphylococcus typhimurium, entre otras) altera significativamente las propiedades de barrera de la membrana exterior del microorganismos (Valenzuela et al., 2012).

La interacción electrostática entre los grupos $\mathrm{NH}_{3}{ }^{+}$del policatión y los grupos fosfolípidos presentes en la membrana celular de bacterias Gram negativas causa daño en esta, provocando la salida de material intracelular. (Liu, 2004); se ha determinado que la salida del material intracelular bacteriano se ve favorecida por grados de desacetilación más altos, tanto en bacterias Gram negativas como Gram positivas. (Chung et al., 2008; Devlieghere et al., 2004; Rabea 2003).

La actividad fungicida del quitosano se ha estudiado, tanto "in vitro" como "in vivo. El quitosano inhibe el desarrollo de numerosas especies de hongos, siendo menos efectivo con aquellas que lo poseen en sus paredes celulares. Los hongos que poseen quitosano como componente de sus paredes celulares deberían ser menos sensibles a la aplicación de dosis razonables de éste por dos razones: (a) la presencia natural de quitosano en las paredes celulares no genera efectos adversos para el microorganismo y (b) las interacciones electrostáticas del quitosano añadido (exógeno), cargado positivamente, deberían verse menos favorecidas con paredes celulares que poseen quitosano endógeno que cuando éstas poseen material con cargas negativas.

La actividad fúngica del quitosano se ha asociado desde hace mucho a su carácter catiónico. La interacción de los grupos aminos libres, cargados positivamente en medio acido con los residuos negativos de las macromoléculas expuestas en la pared de los hongos, cambian la permeabilidad de la membrana plasmática, con la consecuente alteración de las principales funciones (Benhamou, 1992). Otro posible mecanismo de acción fúngico, es que el quitosano se relaciona con la inhibición de la síntesis de algunas enzimas presentes en los hongos o la ocurriencia de alteraciones citológicas, como se ha reportado en el caso de $B$. cinerea, donde se ha observado la aparición de células vacias carentes de citoplasma (Barka et al., 2004) y el Mycophorela Fijensis Morelet (Ayala et al., 2014). 
Los bioestimulantes son una variedad de productos, cuyo común denominador es que contienen principios activos, que actúan sobre la fisiología de las plantas aumentando su desarrollo y mejoran su productividad en la calidad del fruto, contribuyendo a mejorar la resistencia de las especies vegetales, ante diversas enfermedades. En este marco se encuentra la quitosano cuyas propiedades garantizan una efectividad económica y practica superior a otros agentes tradicionales, ya que no produce contaminantes, es biocompatible con tejidos de plantas y animales y antimicrobiano. Su aplicación potencial en la agricultura, es muy importante ya que permite una gran estimulación, germinación, crecimiento y desarrollo de algunas plantas, a la vez que activa mecanismo de defensa en las mismas, los cuales están estrechamente relacionados con la inducción de resistencia sistemática al ataque de microorganismos. (Jiménez et al., 2009). El quitosano cuando se aplica al inicio de la floración a los cultivos es capaz de estimular su crecimiento tanto en tallos, hojas y el tamaño de los frutos y aumentar los rendimientos de los cultivos al compararlos con las plantas que no se le aplicó esta sustancia (Molina, 2015).

Está demostrado que el quitosano produce un aumento del desarrollo del sistema radicular (raices y raicillas) y fortalecimiento del vigor y grado de lignificación de las plantas mediante el mecanismo SAR (Resistencia Sistémica Adquirida). En general la eficiencia de efecto bioestimulante del quitosano se debe a su composición y característica de este polímero, una vez que la planta tiene contacto con este compuesto siente que está en presencia de algún hongo patógeno, e inmediatamente empieza a desarrollar todos sus mecanismos de defensas, esto colateralmente produce un aumento significativo en la raíz, permitiéndole absorber más nutrientes, produciendo un fortalecimiento y mayor vigor en ellas.

Los factores ecológicos determinantes del desarrollo y buen rendimiento del cultivo de arroz, son principalmente la temperatura, el agua, el suelo, luminosidad, la humedad relativa y los vientos. A lo largo del ciclo de cultivo, la temperatura influye en los procesos de germinación, macollamiento, formación de espigas, floración y maduración del grano. Los valores óptimos de este factor, en atención al buen desarrollo de los procesos señalados, oscilan entre los $27^{\circ} \mathrm{C}$ y $34^{\circ} \mathrm{C}$. En lo que al agua se refiere, particularmente con relación a la siembra, más importante que la cantidad de lluvia precipitada, lo es su distribución durante el ciclo de cultivo, ya que existen épocas criticas como lo son la germinación, el crecimiento inicial y la floración en las cuales la suplencia de agua es determinante para la obtención de una buena cosecha.

En la Figura 4 se observa un decrecimientento en el rendimiento de las cosechas de arroz obtenidas en los últimos años, obteniendo para el año 2013 un rendimiento de $4233 \mathrm{~kg}$ por ha de cultivo, esto conlleva a una menor oferta de este rubro de nuestro país, que viene aunada a una demanda creciente de acuerdo al aumento poblacional.

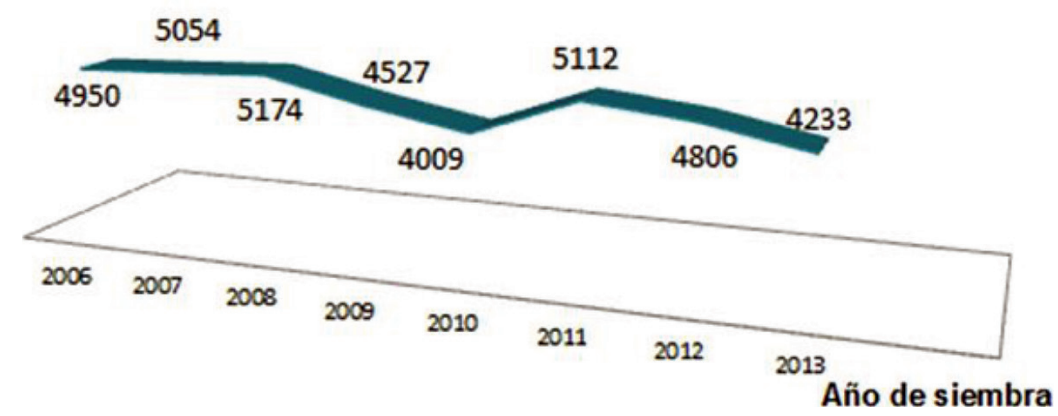

Figura 4. Rendimiento (kg/ha) de arroz sembrado en Venezuela en los últimos años. 
Como se puede observar en la Figura 5, para el año 2013, última data pública registrada, el arroz sembrado fue de 237.440 ha, por lo que es importante obtener un aumento significativo en el rendimiento de cosecha/hectárea, que garantizara un incremento gradual de este cereal para los próximos años, a su vez disminuiría los costos del cultivo y se incrementaría la calidad, convirtiéndolo en un cultivo muy viable económicamente, con buena tasa de rentabilidad (Fedeagro, 2015).

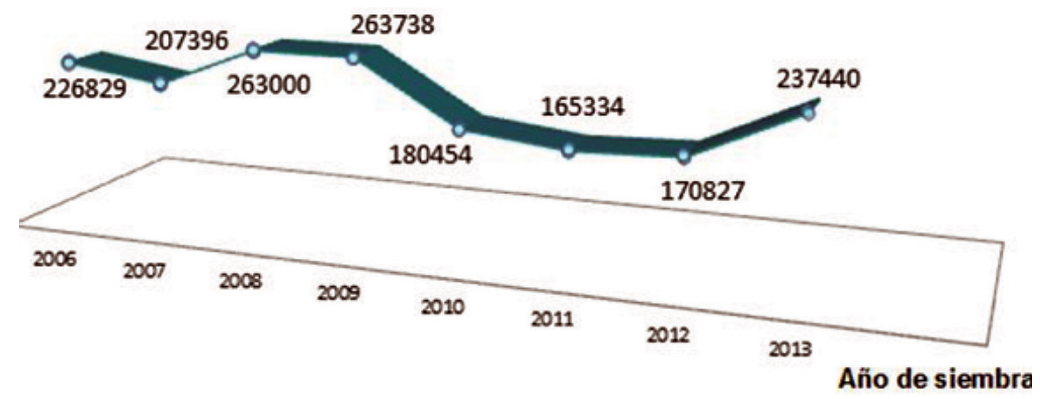

Figura 5. Siembra de arroz (ha) en Venezuela en los últimos años.

Fuente: Fedeagro, 2015

El promedio de rendimiento por hectárea de arroz a nivel mundial es de $3863 \mathrm{~kg}$, esto indica que se está por encima de la media a nivel mundial, pero si se compara Venezuela que tiene suelos prometedores con países como China, donde el rendimiento por hectárea es de $6241 \mathrm{~kg}$, evidencia una deficiencia en la técnica de siembra para con estos cultivos, Venezuela para el año 2011 llegó a producir 5112 kg/ha.

La variedad de arroz SD20A, creada y desarrollada en Venezuela por Fundación Danac, introducida del Centro Internacional de Agricultura Tropical (CIAT, Colombia), con la colaboración del Centro de Cooperación Internacional en Investigación Agrícola para el Desarrollo (CIRAD-Francia). Este cultivo recibió en el año 2008 la elegibilidad para la multiplicación y comercialización de semillas; desde entonces, se ha incrementado la oferta de semillas de este cultivar en respuesta a las necesidades de la cadena agroproductiva del arroz en el país. Danac demostró experimentalmente que la variedad de arroz SD20A posee un alto potencial de rendimiento en campos de agricultores, buena calidad del grano y comprobada resistencia a plagas y enfermedades. Además, la variedad posee una alta tolerancia al retraso de cosecha, lo que significa que su calidad molinera, en cuanto a rendimiento de grano entero, se verá poco afectada si el agricultor realiza cosechas tardías en el campo, siendo una característica altamente deseada en las variedades de arroz. La variedad ha presentado rendimientos en campos de agricultores entre 6.000 y $11.000 \mathrm{~kg} / \mathrm{ha}$, tanto en el ciclo de lluvias como en verano (Danac, 2011).

\section{Materiales y métodos}

\section{Procedimiento experimental}

Todos los reactivos empleados se utilizaron sin ningún método de purificación previa. La desmineralización de la quitina se realizó con $\mathrm{HCl}$ (Riedel-de Haën), $\mathrm{H}_{3} \mathrm{PO}_{4}$ Merck. Para la obtención del 
quitosano se utilizó sulfito de sodio (Merck, G.A.) como agente antioxidante, las reacciones de hidrólisis alcalina se llevaran a cabo con $\mathrm{NaOH}$ (98\%, Riedel-de Haën), y las reacciones de decoloración se llevaron a cabo con etanol (99\%, Fluka, Riedel-de Haën), se solubilizo con ácido acético (99,9\%, Merck.), se utilizaron patrones de quitosano de la casa comercial Sigma-Aldrich ${ }^{\circledR}$. A escala industrial se utilizaron reactivos grado técnico suministrados por la empresa AroQuimica C.A. Se utilizó una balanza digital (Premier) con sensibilidad $\pm 5 \mathrm{~g}$, para el resto del proceso se utilizó una balanza analítica (Kern 440-33N) con sensibilidad $\pm 0,01 \mathrm{~g}$. En las reacciones de obtención de Quitosano ( desproteinización, y desacetilación) se usó un reactor con capacidad de $20 \mathrm{Kg}$ elaborado en acero inoxidable con camisa de calentamiento, válvula de seguridad y enfriamiento con agua. Se empleó un agitador de fabricación propia. El reactor piloto fue diseñado y fabricado por la empresa Innovación Ambiental Quitosano CA, Maracaibo, Venezuela. Para la caracterización fisicoquímica se utilizó: Espectrómetro FTIR marca Shimadzu modelo FTIR 8300, viscosímetro capilar tipo Ubbelhode ASTM D445, estufa (Oven SO-030), mufla (Thermolyne fb131511).

\section{Caracterización del quitosano obtenido}

Para la utilización del Espectrofotómetro de Espectroscopia de Infrarrojo con Transformada de Fourier (FTIR) de la muestra de quitosano se prepararan películas del mismo, disolviendo $250 \mathrm{mg}$ de quitosano en $50 \mathrm{~mL}$ de ácido acético al 6\% (v/v) formándose un gel transparente y viscoso, este gel se coloca en moldes plásticos con un área de $13 \mathrm{~cm}$ de diámetro y luego se secaron a temperatura ambiente en ausencia de luz hasta la obtención de la película. Los espectros obtenidos se compararon con un patrón comercial de la casa Sigma-Aldrich, comprobando la obtención del polímero.
Para la determinación de la masa molecular viscosimétrica (Mv) se usó la aproximación de MarkHouwink-Sakurada (MHS) aplicando las ecuaciones de relación entre viscosidades de solvente y soluciones de $1 \mathrm{mg} / \mathrm{ml}$ de quitosano. Para determinar la viscosidad intrínseca $\left(\mathrm{h}_{\mathrm{int}}\right)$, del quitosano obtenido, se prepara por disolución una mezcla compuesta de ácido acético $0,1 \mathrm{M}$ y cloruro de sodio $0,2 \mathrm{M}$. Se usara un viscosímetro capilar. Se medirán los tiempos de caída entre las marcas de referencia del viscosímetro de las soluciones preparadas con el fin de determinar la viscosidad intrínseca $\left(\mathrm{h}_{\mathrm{in}}\right)$.Con los valores de viscosidad intrínseca se determina la masa molar viscosimétrica $(\mathrm{Mv})$, donde las constantes para el sistema de solvente $0,1 \mathrm{M} \mathrm{CH} \mathrm{CH}_{3} \mathrm{COOH} / 0,2 \mathrm{M} \mathrm{NaCl}$ son $\mathrm{K}=1,83 \times 10^{-3}, \mathrm{a}=0$,93. (Nieto, et al., 1991, González et al., 2015; Perentena et al., 2015).

\section{Evaluación del quitosano en el cultivo de arroz (variedad SD20A)}

Se determinó a través de las propiedades y características del quitosano obtenido, cual presentaba las mejores condiciones para aplicarlo en cultivos de arroz. Seguidamente se prepararon geles del quitosano, diluyendo $25 \mathrm{~g}$ del quitosano en $5 \mathrm{ml}$ de ácido acético, agitándolo hasta formarse el gel, luego se diluye a $1 \mathrm{~L}$. De esta solución se tomaron $2 \mathrm{cc}$ de quitosano $/ \mathrm{kg}$ de arroz. El ensayo se realizó por triplicado en tres diferentes fincas en el Estado Apure, Venezuela. El arroz se tomó de la variedad SD20A. Se evaluó el tamaño, color, vigor y raíces de las plántulas de arroz durante 41 días aproximadamente después de la germinación y se comparan con las que no se les aplicó quitosano. La variedad de arroz SD20A fue obtenida en los procesos de investigación de Fundación Danac, se produjo mediante convenios con diversas empresas a partir de semilla básica suministrada por este centro de investigación. 


\section{Resultados}

\section{Caracterización del Quitosano}

En la Figura 6 se pueden observar los espectros FTIR de los quitosanos obtenidos por medio de la desacetilación parcial de las quitinas desmineralizadas con dos ácidos diferentes: ácido clorhídrico y ácido fosfórico.

En la Figura 7 se observan los resultados de la Masa Molar para los distintos Quitosano obtenidos con diferentes ácidos y con respecto al Quitosano comercial.

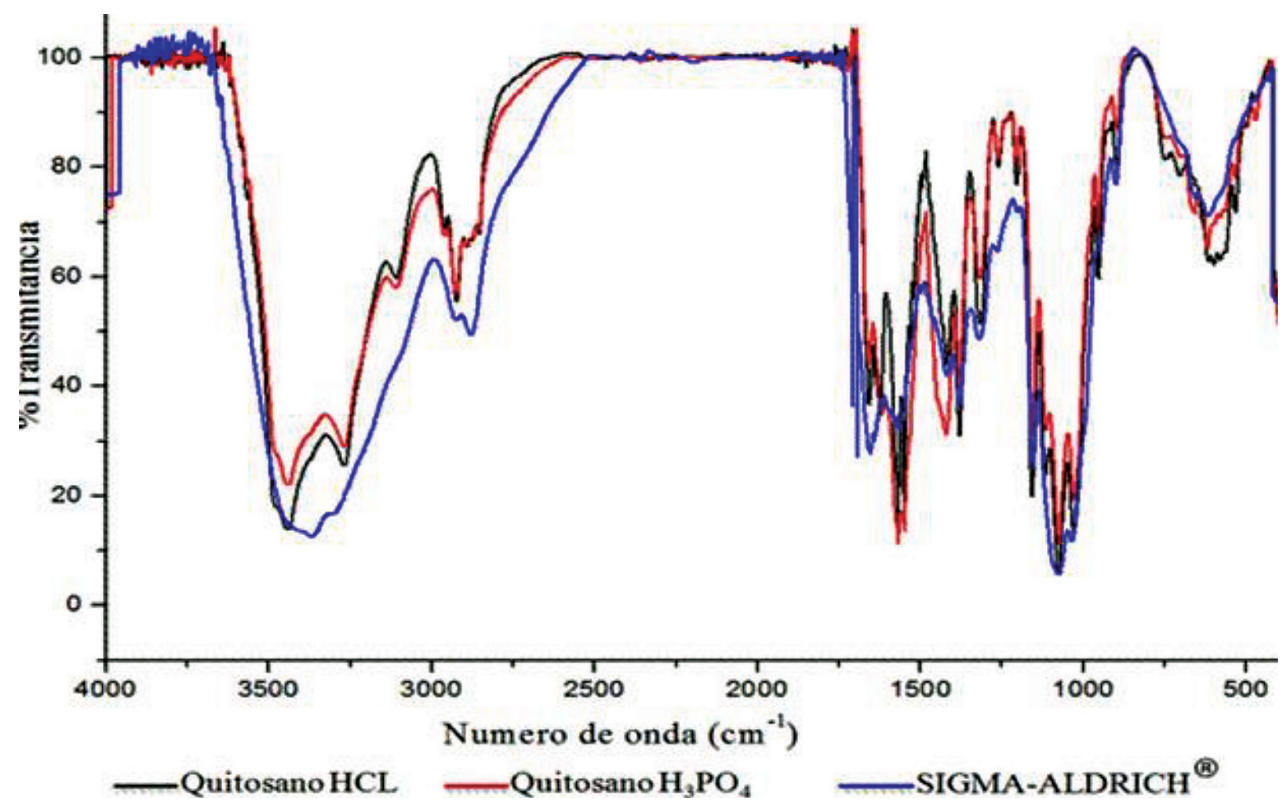

Figura 6. Espectro FT-IR de Quitosano Comercial (Sigma-Aldrich) y de los obtenidos de las quitinas desmineralizadas con distintos ácidos: ácido clorhídrico y fosfórico.

\section{Mv del Quitosano Obtenido y Comercial (KDa)}

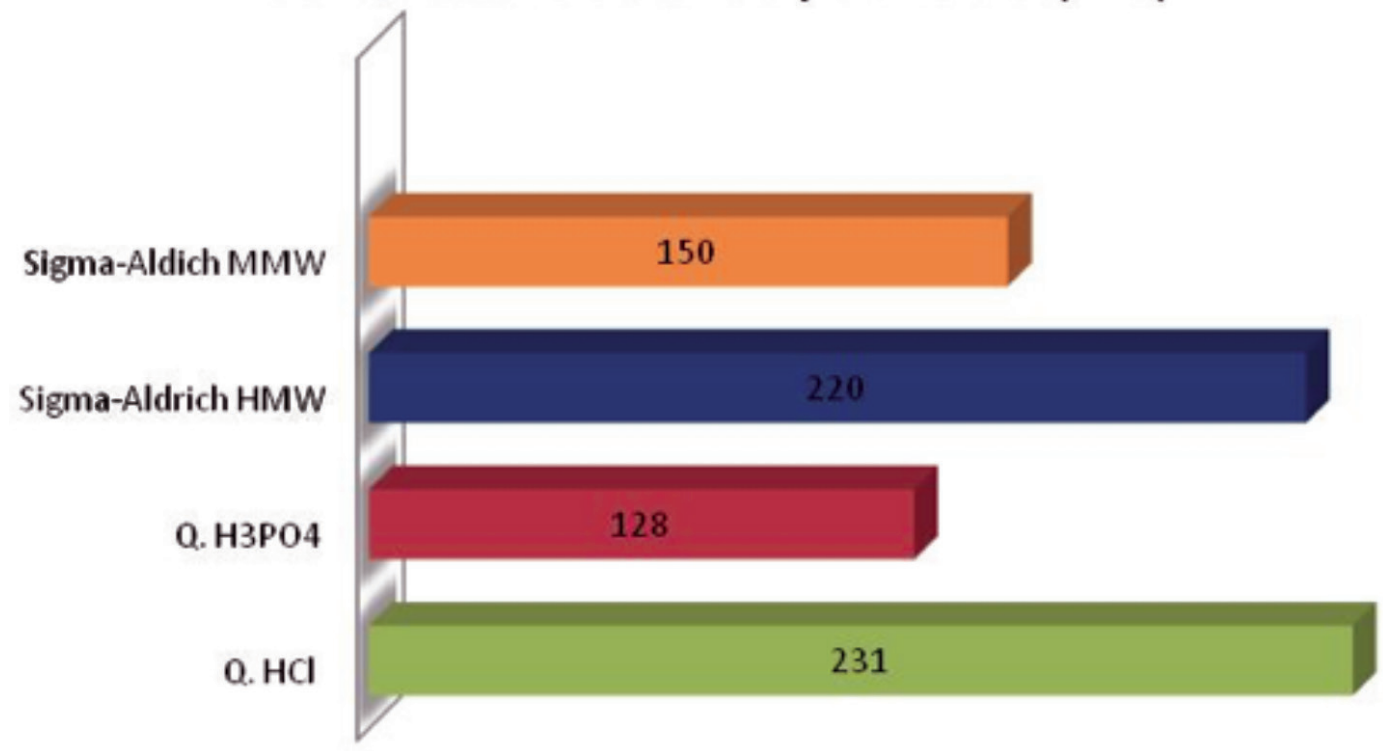

Figura 7. Resultados de la Masa Molar de los quitosanos obtenidos con ácido clorhídrico y ácido fosfórico con respecto al Quitosano comercial Sigma Aldrich. 


\section{Evaluación para la aplicación del quitosano obtenido, en forma de gel en cultivos del arroz variedad SD20A.}

Una vez determinada las características del quitosano utilizando en el proceso de extracción ácido fosfórico, se sometió a evaluación en cultivos de arroz (Oryza sativa), variedad SD20A.

Impregnación de semilla con quitosano. El tratamiento de semilla se realiza para preservarla de hongos y microorganismos del suelo o que se trasmiten por la propia semilla. El mismo puede ser seco o húmedo, existiendo varias tecnologías que van desde un proceso manual hasta el uso de sofisticados equipos (Olmos, 2007). Se realizó la impregnación uniforme de las semillas de arroz con una concentración de 2,5\% gel de quitosano a una proporción de $2 \mathrm{cc} / \mathrm{Kg}$ de semilla (Rodríguez et al., 2004), reportaron concentraciones similares para la impregnación de semillas de arroz, encontrando mayor efecto en soluciones viscosas, por lo que debe adherirse mejor a la semilla y su liberación debe ser más lenta que las soluciones menos concentradas a las propuestas, trayendo como consecuencia más tiempo en contacto con las semillas. El tratamiento debe realizarse sólo unos días antes de la siembra, ya que periodos largos de almacenamiento después de ser aplicado algún producto sobre la simiente puede afectar la condición biológica de la misma, La Tabla 1 muestra las diferencias en porcentajes con y sin aplicación de quitosano.
Tabla 1. Diferencias en porcentajes de germinación con y sin aplicación de quitosano.

Germinación en las semillas de arroz (\%)

\begin{tabular}{|l|l}
\hline Sin gel de quitosano & $\mathbf{8 2} \pm 2,64$ \\
\hline $\begin{array}{l}\text { Con gel de quitosano al } \\
2,5 \%(2 \mathrm{cc} / \mathrm{kg} \text { de semilla) }\end{array}$ & $\mathbf{8 7} \pm \mathbf{3 , 2 0}$ \\
\hline
\end{tabular}

Incrementos del crecimiento de las plantas a 12, 30 y 60 días, en el cultivo de arroz (Oriza sativa variedad SD20A).

Para estas mediciones se utilizó un diseño completamente aleatorizado y con tres repeticiones por tratamiento, se utilizó un cuadro de $1 \mathrm{~m}^{2}$, lazándose al azar en tres partes distintas por hectárea, extrayendo 6 plantas por medición para un total de 18 muestras en cada uno de los casos. Los cultivos de arroz, tienen una duración alrededor de 120 días, pero su crecimiento vegetativo oscila hasta los 60 días de siembra, razón por la cual en este trabajo la última medición se realiza el día 60. (Rodríguez et al., 2004). En la Tabla 2, se observan las diferencias expresadas en centímetros entre el cultivo testigo y el cultivo utilizado con gel de quitosano. A las muestras testigo se les aplico un tratamiento convencional y a las muestras tratadas con quitosano, adicional al tratamiento convencional se realizó el proceso de desinfección de semilla y se asperjo a los 30 días de siembra en una proporción de 2 L/ha a una concentración de 2,5\%.

Tabla 2. Altura de la plantas a los 12, 30 y 60 días de siembra para los diferentes tratamientos.

\begin{tabular}{|c|c|c|c|c|c|c|}
\hline & \multicolumn{2}{|c|}{12 días } & \multicolumn{2}{|c|}{30 días } & \multicolumn{2}{|c|}{60 días } \\
\hline & $\mathrm{T} 1$ & T2 & $\mathrm{T} 1$ & T2 & $\mathrm{T} 1$ & T2 \\
\hline \multirow{2}{*}{$\begin{array}{l}\text { Altura de la } \\
\text { planta }(\mathrm{cm})\end{array}$} & 15,86 & 19,01 & 54,88 & 60,44 & 75,92 & 86,73 \\
\hline & $\pm 3,25$ & $\pm 2,84$ & $\pm 1,80$ & $\pm 4,20$ & \pm 5.79 & $\pm 3,42$ \\
\hline
\end{tabular}

La aplicación de elicitores como el quitosano, es uno de los métodos más ecológicos y económicos para el control de plagas y enfermedades, además de mantener a las plantaciones protegidas con un alto sistema de defensas. (Rodríguez et al., 2004).
En la Figura 8, se detalla el incremento del porcentaje con respecto a la altura en cada una de las fases del cultivo, demostrando un aumento en la altura del tratamiento del quitosano con respecto al testigo de hasta $16,57 \%$. 


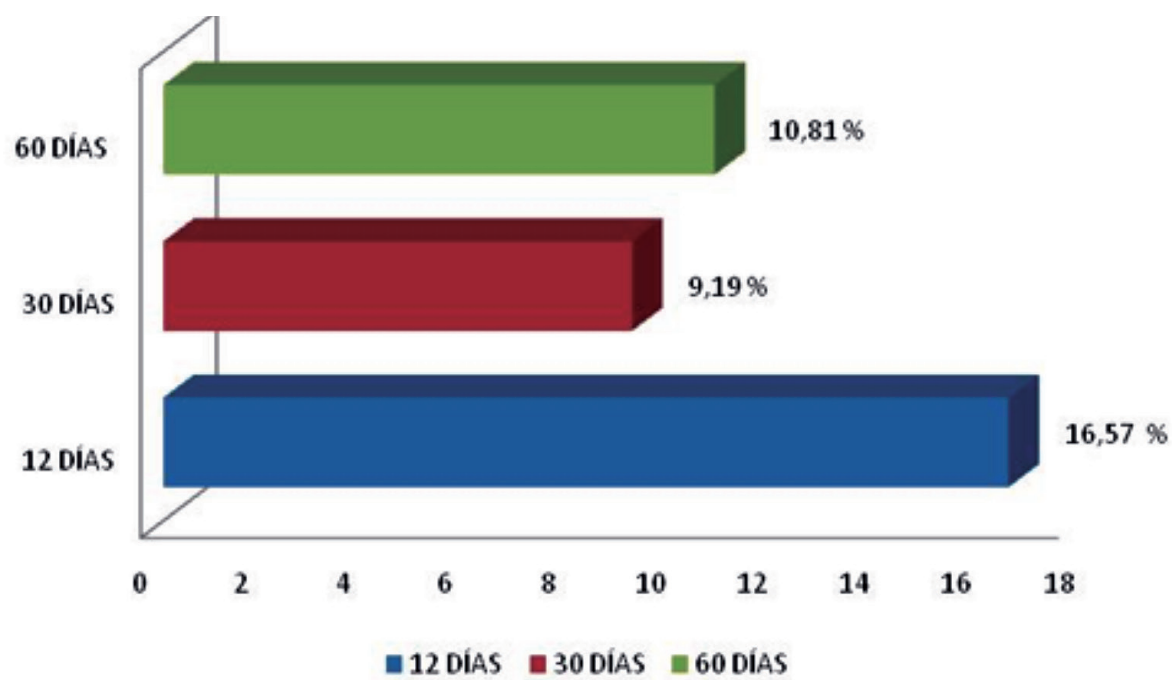

Figura 8. Incremento en porcentajes de las mediciones en el cultivo (quitosano vs testigo).

Incrementos del crecimiento de las raíces en porcentajes a 12, 30 y 60 días, en el cultivo de arroz (Oriza sativa variedad SD20A).

Se realizó un seguimiento visual al desarrollo de las plántulas, en cuando a raíces, vigor y tamaño, a los 12, 16 y 19 días, a través de procedimientos anteriormente explicados, con la finalidad de determinar el momento en la etapa de crecimiento en que la planta pasa a la fase de macollamiento. En la Figura
9, se observa el estado de las plántulas de arroz a los 12 días de germinación, en la fotografía $(A)$ donde el cultivo no posee quitosano, se muestra una baja cantidad de raíces, menor vigor en las plántulas y menor crecimiento, a diferencia de la fotografía (B) donde el cultivo se le aplico quitosano. En la Figura 10, se observa el estado de las plántulas de arroz a los 16 días de germinación, en la fotografía (A) donde el cultivo no posee quitosano.
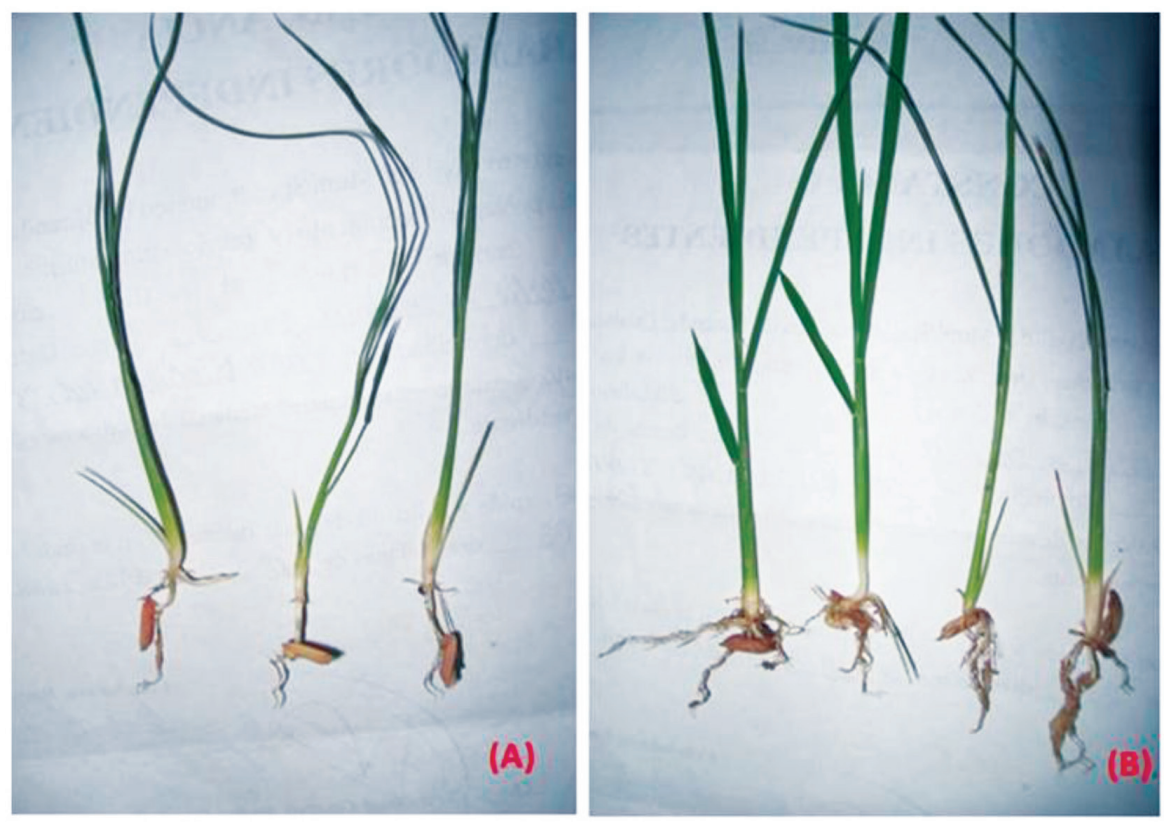

Figura 9. Plántulas de arroz, a los 12 días de germinación. (A) Desinfección de semilla sin quitosano. (B) Desinfección de semilla con quitosano. 

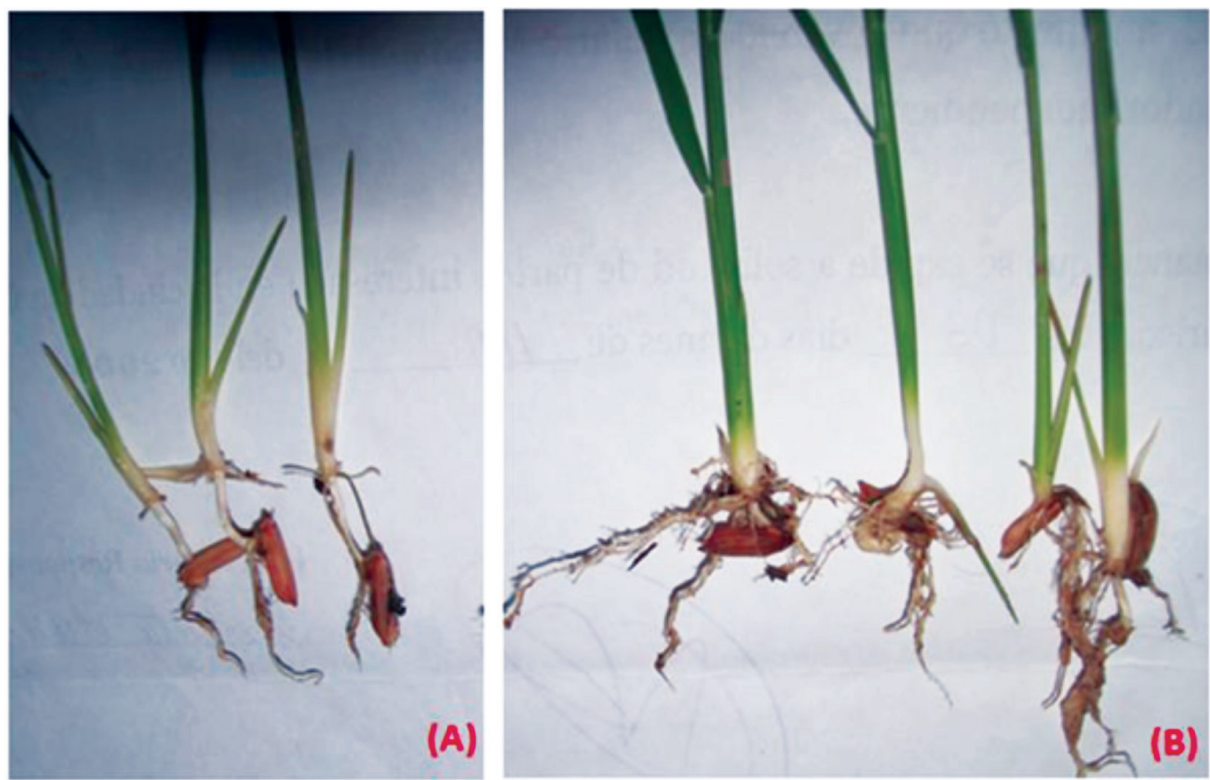

Figura 10. Plántulas de arroz, a los 16 días de germinación. (A) Desinfección de semilla sin quitosano. (B) Desinfección de semilla con quitosano.

En este estudio se utilizó la variedad de arroz SD20A, creada y desarrollada en Venezuela por Fundación Danac, introducida del Centro Internacional de Agricultura Tropical (CIAT, Colombia), con la colaboración del Centro de Cooperación Internacional en Investigación Agrícola para el Desarrollo
(CIRAD-Francia). (Danac, 2017).En la Figura 11, se observa el estado de las plántulas de arroz a los 19 días de germinación, en la fotografía (A) donde el cultivo no posee Quitosano. En la Figura 12, se observa el incremento de porcentaje en peso seco de las raíces para 12, 30 y 60 días de siembra.

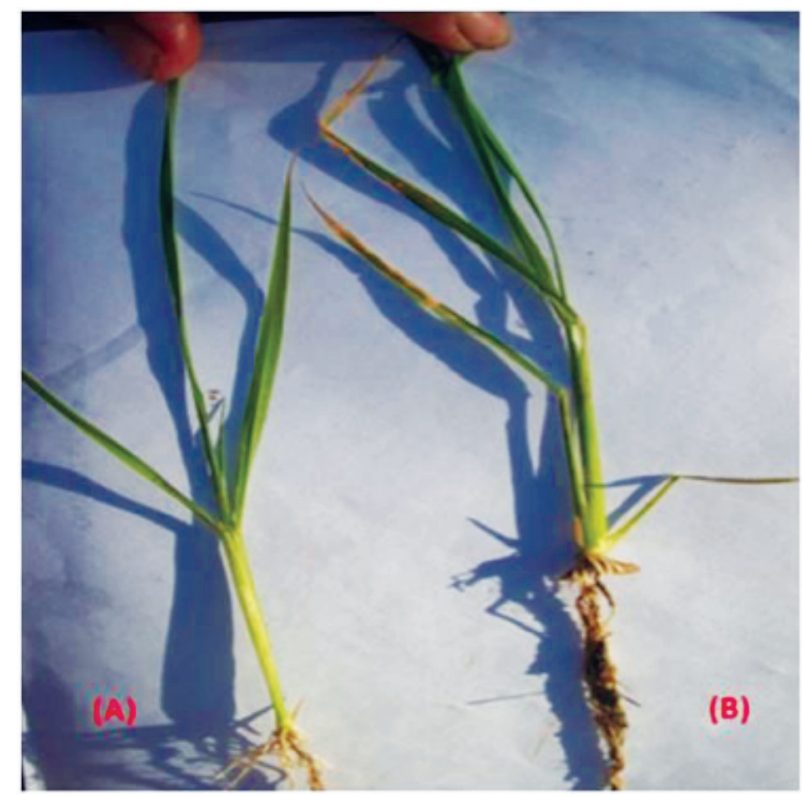

Figura 11. Plántulas de arroz, a los 19 días de germinación. (A) Desinfección de semilla sin quitosano. (B) Desinfección de semilla con quitosano. 


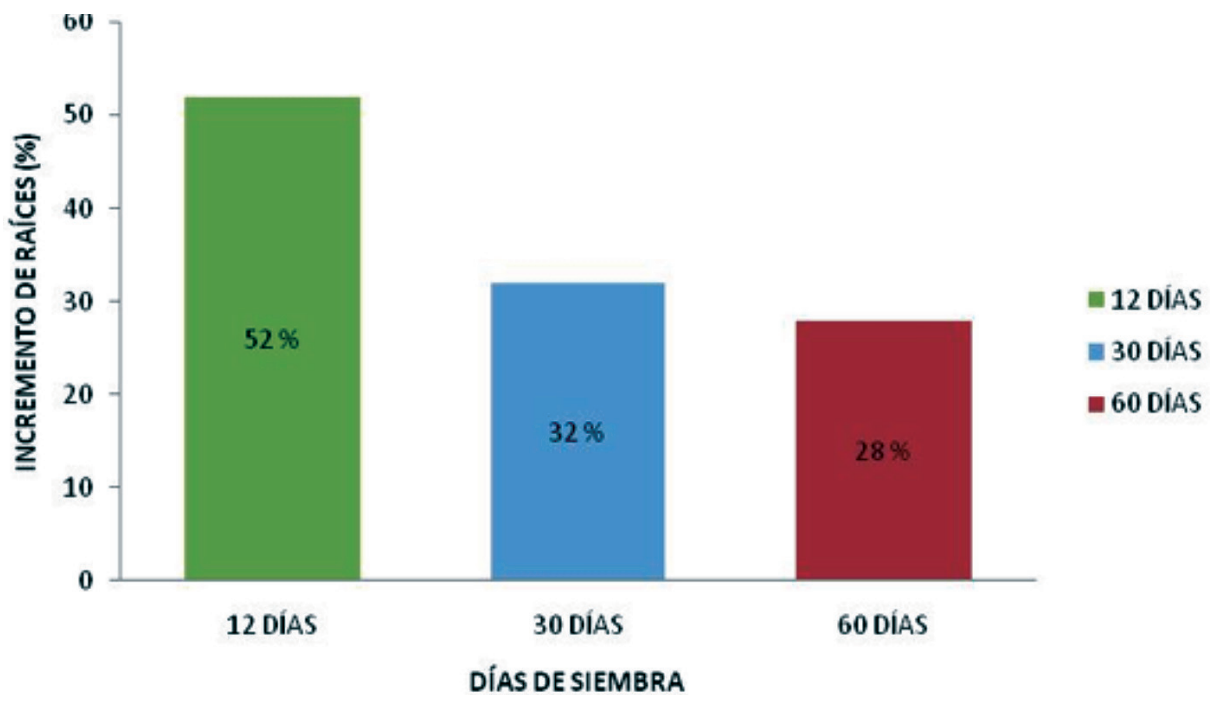

Figura 12. Incremento expresado en porcentaje de peso seco en las raíces para 12, 30, 60 días de siembra.

Se comparó el rendimiento de cultivo tratado con quitosano (con un tratamiento de desinfección de semilla de $2 \mathrm{cc} / \mathrm{kg}$ de gel de quitosano al 2,5\%, y una aplicación a los 30 días de 2 L/ha al 2,5\% de quitosano. En la Tabla 3, se muestra el rendimiento obtenido por ha de siembra en cada uno de los tratamientos.

Tabla 3. Rendimiento de cosecha por ha sembrada.

\begin{tabular}{l|c|c}
\hline & Tratamiento con quitosano & Tratamiento sin quitosano \\
\hline $\begin{array}{l}\text { kg cosechado/ } \\
\text { ha de Siembra }\end{array}$ & 6320 & 5295 \\
\hline
\end{tabular}

\section{Discusión}

\section{Caracterización del Quitosano}

Se pueden observar las bandas de los grupos funcionales característicos de la molécula de quitosano, evidenciándose la aparición de la banda del grupo amino a $1621 \mathrm{~cm}^{-1}$ y se observa una mejor definición de las bandas de los grupos $\mathrm{OH}$ a $3447 \mathrm{~cm}^{-1}$ y N-H a $3258 \mathrm{~cm}^{-1}$ (Figura 6). En lo que respecta a las bandas encontradas para ambas muestras, resultaron acordes a las características del quitosano comercial (SIGMA-ALDRICH) (Yu et al., 2009; Kumirska et al., 2010; León et al., 2017). El análisis mediante IR mostró la similitud en los espectros para cada una de las muestras, confirmando con estos resultados que la utilización de diferentes quitinas obtenidas por la desmineralización con $\mathrm{HCl}$ y $\mathrm{H}_{3} \mathrm{PO}_{4}$ no afectó la identidad del producto, pues se mantienen las bandas de los grupos funcionales más importantes, demostrándose así que las quitinas se transformaron en una nueva materia prima como el quitosano. La diferencia de Mv (masa molar) entre los resultados reflejados (Figura 7), para el quitosano extraído con $\mathrm{HCl}$ y $\mathrm{H}_{3} \mathrm{PO}_{4},(231 \pm 5,03$ y $128 \pm 6,11 \mathrm{KDa}$ respectivamente), es debido a las diferentes propiedades de estos ácidos, en el caso del clorhídrico siendo un ácido fuerte, las concentración a las que se utiliza es menor, esto conlleva a una menor degradación en la cadena polimérica; en el caso del ácido fosfórico, siendo este un ácido débil y menos efectivo, amerita concentraciones mayores, sumado a esto la presencia de oxígeno en la estructura de este acido degrada de manera considerable las cadenas poliméricas. Se evidencia valores inferiores de Mv para los quitosanos comerciales (Colina et al., 2015). Es importante destacar 
el tipo de la fuente de donde provienen, se ha reportado que en el caso de quitosano obtenidos de camarones, la masa molecular es considerablemente más baja, a los quitosanos obtenidos de cangrejos, a nivel mundial un $70 \%$ del quitosano comercial proviene de fuentes de camarones.

\section{Evaluación para la aplicación del quitosano obtenido, en forma de gel en cultivos del arroz variedad SD20A.}

La aplicación de quitosano ha mostrado efectos positivos en el crecimiento de las plantas, tanto en la estimulación de germinación de semillas como en el crecimiento de partes de la planta como raíces, retoños y hojas. (Lárez et al., 2008). En la Tabla 1 , se puede observar diferencias entre los porcentajes de germinación de las semillas impregnadas con quitosano y las que no fueron impregnas, estos se relacionan con los encontrados por Lárez et al. (2008), en donde se ha observado que la estimulación de la germinación de semillas por tratamiento con quitosano ha logrado elevar el porcentaje de germinación en diferentes cultivos. En este caso se obtuvo un incremento de $5 \%$ en la germinación, esto es muy importante teniendo en cuenta la cantidad de hectáreas sembradas de este cultivo en Venezuela y el mundo, es por esto que al lograr aumentar el porcentaje de germinación se estaría incrementando directamente los rendimientos del cultivo por hectárea en este rubro. En otros trabajos donde se trataron semillas de arroz con quitosano y uno de sus oligomeros, se observó también que había inducción de la actividad del quitosano en el proceso de germinación, lo cual afirma los resultados obtenidos. (Rodríguez et al., 2004).

Los resultados arrojados en la Tabla 2, demuestran los beneficios del quitosano, este tiene la potencialidad de inhibir numerosos hongos fitopatógenos y de estimular los mecanismos de defensas de las plantas, lo que garantiza un buen tamaño de las mismas en los cultivos (Olmos, 2007). Aunque en este trabajo solo se está evaluando el quitosano en el crecimiento de la planta, una de las causas de los bajos rendimientos a nivel mundial de este cultivo, son los daños causados por las enfermedades y en especial las de origen fungoso, siendo entre los 25 y 35 días donde la planta muestra mayor susceptibilidad, se puede denotar que en este trabajo los resultados a los 30 días de las plantas con quitosano poseen una altura de 60,84 cm superior por 9,19\% (Figura 10), al tratamiento convencional. Se ha demostrado que cuando este tipo de cultivos presentan activo macollamiento (raíces), un gradual incremento de la altura de las plantas, y la emergencia de las hojas a intervalos regulares, dan lugar a un buen rendimiento de cosecha en el cultivo. (Jiménez et al., 2009).

\section{Incrementos del crecimiento de las raíces en porcentajes a 12, 30 y 60 días, en el cultivo de arroz (Oriza sativa variedad SD20A).}

En la Figura 11, en la fotografía (A) donde el cultivo no posee quitosano, se muestra una baja cantidad de raíces, menor vigor en las plántulas y menor crecimiento, a diferencia de la fotografía (B) donde el cultivo se le aplico quitosano. Esto también se observa en las Figuras 10, 11 y 12. Además en la Figura 11, también se observa el macollamiento que comienza cuando la plántula está establecida (15 - 20 días) y generalmente termina cuando se inicia el desarrollo del primordio floral, a diferencia de la fotografía $(A)$ en la cual la plántula no presenta ningún macollamiento, esto quiere decir que aún no ha terminado de establecerse para la siguiente etapa vegetativa que es el macollaje. Nótese el número de hojas fundamental en el desarrollo de estos cultivos, a los 19 días de germinación la fotografía (A) presenta 4 hojas y en la fotografía (B) tratamiento con quitosano presenta 5 hojas.

El quitosano tiene la propiedad de hacer más eficiente el desarrollo del arenquima, el cual mejora la distribución del oxígeno hacia las raíces, lo que conlleva a un mejor desarrollo de la planta. Al conferir resistencia a la pared celular vegetal, permite a las plantas tratadas resistir en mejor forma el stress hídrico, tanto el exceso como la falta de agua y, por tal motivo, se han observado buenos resultados en arroz y en plantas creciendo bajo condiciones de sequía, en plantaciones y cultivos en suelos rojo-arcillosos, en plantas creciendo en suelos con poca disponibilidad de agua, etc. En este mismo sentido, el quitosano protege a las raíces de las plantas tratadas de las pérdidas de 
agua o deshidrataciones normales al momento del transplante, permitiendo un mejor y rápido crecimiento radicular de las plantas tratadas en suelos con bajo nivel de agua. El uso potencial está en ciertas zonas de inferior condición de suelo destinadas al desarrollo agropecuario y en sectores de poca disponibilidad de agua de riego. (González et al., 2009). En la Figura 12 se observa que para 12 días las plántulas en etapa de crecimiento vegetativo obtuvieron hasta un $52 \%$ por arriba en peso seco de raíz, estos incrementos de raíces en cada una de las etapas del cultivo, representan un gran beneficio en cuanto al anclaje y absorción de nutrientes de las plantas, permitiendo un mayor y mejor desarrollo del cultivo como se ha venido presentando en los diferentes resultados antes expuestos. En la Figura 12 se puede asumir que como el quitosano sirve como filtrante de las radiaciones UV, y adicionalmente considerando sus propiedades antifúngicas, se resume que la planta estará mucho más protegida del sol. (Lárez et al., 2006; Rivero et al., 2009).

En la Tabla 3 se encontró una diferencia de 1025 $\mathrm{kg} / \mathrm{ha}$, y un incremento en la cosecha de 16,21\% con respecto al tratamiento sin quitosano. De conformidad con los resultados obtenidos en la presente investigación se ha demostrado que el cultivo de arroz, variedad SD20A, tuvo un desarrollo vegetativo diferente de acuerdo al tratamiento al que fue sometido. Estos rendimientos de cosecha superiores al del tratamiento sin quitosano, eran de esperarse de acuerdo al seguimiento desde la etapa de germinación hasta la etapa de crecimiento vegetativo. Los bioestimulantes como el quitosano contienen principios activos, que actúan sobre la fisiología de las plantas aumentando su desarrollo y mejorando su productividad en la calidad del fruto, contribuyendo a mejorar la resistencia de las especies vegetales y su rendimiento. (Jiménez et al., 2009, Rivero et al., 2009). Evaluando la factibilidad económica con el uso del quitosano, un rendimiento como los expresados en la Tabla 3, con incrementos de cosecha 16,21\%, demuestran una disminución de costos por hectárea, una mayor utilidad del cultivo, a su vez garantiza el pago del producto, sin generar un costo adicional en el ciclo de este rubro.

\section{Conclusiones}

Se observa un incremento en la etapa de germinación de semilla con quitosano. Las plantas tratadas presentaron alturas mayores a las que no fueron tratadas con este polímero. Además, se observó en las plantas de arroz un color verde más intenso, estos resultados se deben a la capacidad estimulante del quitosano, ya que actúa mejorando el enraizamiento y la producción de área foliar de la planta, lo que aumenta los niveles de clorofila y mejora el índice de asimilación neta para permitir un llenado del grano más eficiente y rápido.

El rendimiento de cosecha encontrado tuvo una relación directa con el comportamiento del cultivo en todas sus fases vegetativas, marcando diferencias significativas en las características de las plantas estudiadas, incrementando la producción 16,21\% / ha.

\section{Literatura citada}

1. Aranaz, I., Mengíbar, M., Harris, R., Paños, I., Miralles, B., Acosta, N., Galed, G. \& Heras, Á. (2009). Functional Characterization of Chitin and Chitosan. Current Chemical Biology, 3, 203-230

2. Ayala, A., Colina, M., Molina, J., Vargas, J., Rincón, D., Medina, J., Rosales, L. \& Cárdenas, H., (2014). Evaluación de la actividad antifúngica del Quitosano contra el hongo Mycophorella Fijensis Morelet que produce la Sigatoka Negra que ataca el plátano. Revista Iberoamericana de Polímeros y Materiales. 15, 312-338.

3. Barka, E. A., Eullaffroy, P., Climent, C. \& Vernet, G. (2004). Chitosan improves development, and protects Vitis vinifera L. against Botrytis cinerea. Plant Cell Reports 22, 608-614.

4. Benhamou, N. (1992). Ultrastructural and cytochemical aspects of chitosan on Fusarium oxysporum f. sp. radicis-lycopersici, agent of tomato crown and root rot. Phytopathology 82, 1185-1193.

5. Chung, Y.C. \& Chen, C.Y., (2008). Antibacterial characteristics and activity of acid-soluble chitosan. Bioresource Technology, 99, 2806-2814.

6. Colina, M., Ayala, A. Rincón, D., Molina, J., Medina, J., Ynciarte, R., Vargas, J. \& Montilla, B. (2014). Evaluación de los procesos para la obtención química de quitina y Quitosano a partir de los desechos de cangrejos. Revista Iberoamericana de Polímeros y Materiales, 15(1), 21-43.

7. Costa, C., Teixeira, V., Marcia C., Delpecha, J., Souza, V. \& Costa, M. (2015). Viscometric study of chitosan solutions in acetic acid/sodium acetate and acetic 
acid/sodium chloride. Carbohydrate Polymers, 133, 245-250.

8. Danac. (2011). Workshop on Data analytics at sCale. Recuperado de: http://danac.org.ve/wp-content/ uploads/Conexion-Danac-abril-2011-especial.pdf

9. Devlieghere, F., Vermeulen, A. \& Debevere, J. (2004). Chitosan: antimicrobial activity, interactions with food components and applicability as a coating on fruit and vegetables. Food Microbiology, 21, 703-714.

10. Fedeagro - Confederación de Asociaciones de Productores Agropecuarios. (2015). Estadísticas Agropecuarias en Cereales. Recuperado de: http://www.fedeagro.org/produccion/Rubros.asp.

11. González, D., Cruz, A., Martínez, B., Ramírez, M. \& Rodríguez, A. (2009). Actividad antifúngica in vitro de la quitosana Sigma frente a hongos fitopatógenos causantes del manchado del grano en el cultivo de arroz (Oryza sativa L.). Fitosanidad, 13, 2.

12. González, C., Valbuena, A., Celis, B., Perentena, L. \& Colina, M. (2015). Degradación oxidativa de quitosano con peróxido de hidrógeno. Revista Iberoamericana de Polímeros y Materiales, 16,1, 43-68.

13. Jiménez N., Jiménez M., Falcón A., Gonzáles G. \& Silvente J. (2009). Evaluación de tres dosis de quitosano en el cultivo de pepino en un periodo tardío. Revista Electrónica de la Ciencia en Granma, 13, 1-6.

14. Kasaai, M. (2008). A review of several reported procedures to determine the degree of $\mathrm{N}$-acetylation for chitin and chitosan using infrared spectroscopy. Carbohydrate Polymers, 71, 497-508.

15. Kumirska, J., Czerwicka, M., Kaczynski, Z., Bychowska, A., Brzozowski, K., Thöming, J. \& Stepnowski,P. (2010). Application of Spectroscopic Methods for Structural Analysis of Chitin and Chitosan. Mar. Drugs., 8, 1567-1636.

16. Kurita, K. (2006). Chitin and chitosan: Functional biopolymers from marine crustacean. Marine Biotechnology, 8,203-226.

17. Lárez, C. (2006). Quitina y quitosano: materiales del pasado para el presente y el futuro. Avances en Química, 1, 15-21.

18. Lárez C., Sánchez, J. \& Millán, E. (2008). Viscosimetric studies of chitosan nitrate and chitosan chlorhydrate in acid free $\mathrm{NaCl}$ aqueous solution. Polymer. 14-18.

19. León, O., Muñoz-Bonilla, A., Soto, D., Ramírez, J., Márquez, Y., Colina, M. \& Fernández-García, M. (2017). Preparation of oxidized and grafted chitosan superabsorbents for urea delivery. Journal of Polymers and the Environment, doi: 10.1007/s10924-017-0981-x2017.

20. Li, Y., Chen, X., Liu, C., Liu, C., Meng, X., Yu, L. \& Kenendy, J. (2007). Physicochemical characterization and antibacterial property of chitosan acetates. Carbohydrate Polymers, 67, 227-232.

21. Liu, H., Du, Y., Wang, X. \& Sun, L. (2004). Chitosan kills bacteria through cell membrane damage. International Journal of Food Microbiology, 95, 147-155.

22. Molina, J. (2015). Desmineralización de la quitina utilizando ácido fosfórico para la obtención de quitosano y su aplicación en el cultivo de arroz. (Tesis Master). Universidad del Zulia. Venezuela.

23. Nieto, J., Peniche, C. \& Padrón, G. (1991). Characterization of chitosan by pyrolysis-mass spectrometry, thermal analysis and differential scanning calorimetry. Thermochimica Acta, 176, 63-68.

24. Olmos, S. (2007). Apuntes de morfología, fenología, ecofisiología, y mejoramiento genético del arroz. Cátedra de Cultivos II Facultad de Ciencias Agrarias, UNNE. Recuperado de: http://www.acpaarrozcorrientes.org.ar/academico/Apunte-MORFOLOGIA.pdf

25. Perentena, L., González, C., Celis, B., Valbuena, A. \& Colina, M. (2015). Síntesis de bases de Schiff derivadas de Quitosano por reacción con p_dimetilamino benzaldehído y 4-hidroxi-3-metxibenzaldehído. Revista Iberoamericana de Polímeros y Materiales, 16,1, 1-27.

26. Rabea, E., Badawy, M., Stevens, C., Smagghe, G. \& Steurbaut, W. (2003). Chitosan as antimicrobial agent: Aplications and mode of Action. Biomacromolecules, 4 (6), 1457-1465.

27. Rivero D., Cruz A., Martínez B., Ramírez M. \& Rodríguez, A. (2009). Actividad antifúngica in vitro de la quitosana sigma frente a hongos fitopatógenos causantes del manchado del grano en el cultivo de arroz (Oriza Sativa).Fitosanidad, 13, 101-107.

28. Rodríguez A., Rodríguez M., Falcón A., Guridi F. \& Cristo E. (2004). Estimulación de algunas enzimas relacionadas con la defensa en plantas de arroz (Oryza Sativa) obtenidas de semillas tratadas con quitosana. Cultivos tropicales, 25, 111-115.

29. Valbuena, A., Valbuena, C., Colina, M. \& Diaz, N. (2012). Synthesis of chitosan derivatives with antifungal and antibacterial properties. Adv. in Chitin Sc., XIV.

30. Valenzuela, C. \& Arias, J. (2012). Potenciales aplicaciones de películas de quitosano en alimentos de origen animal. Avan. Cien. Veter., 27: 33-47.

31. Xing, W., Zhao, Y. \& Zuo, J. (2009). Microbial activity and community structure in a lake sediment used for psychrophilic anaerobic wastewater treatment. Journal of Applied Microbiology, 109, 1829-1837.

32. Yu, T., Li, H.Y. \& Zheng, X. (2007). Synergistic effect of chitosan and Cryptococcus laurentii on inhibition of Penicilliumexpansum infections. International Journal of Food Microbiology, 114, 261-266.

33. Zemmouri H., Drouiche M., Sayeh A., Lounici H. \& Mameri N. (2012). Coagulation Floculation test of Keddara's Water Dam Using Chitosan and Sulfate Aluminium. Procedia Engineering, 33, 254-260.

Conflicto de Intereses

Los autores declaran no tener ningún conflicto de intereses

Recibido: Enero 23 de 2017 Aceptado: Marzo 10 de 2017 